\title{
Production of biodiesel from rice bran oil
}

\begin{abstract}
Rice bran is a byproduct of the milling process of paddy rice to produce refined rice. Rice bran oil (RBO) is a valuable domestic oil resource in many countries, its acceptability as an edible oil has been hampered because of its commonly high free fatty acid (FFA) content resulting from the high lipase activity of the bran. Depletion in nonrenewable sources, especially for petroleum diesel and fossil fuel, has alarmed the global community into looking for an alternative way to overcome this situation. One of the alternatives is using RBO as the source to produce biodiesel. This chapter highlights the properties of $\mathrm{RBO}$, extraction of $\mathrm{RBO}$, different processes in the production of biodiesel using RBO, and the characteristics of this oil that are suitable for biodiesel production. The future and challenges of biodiesel are also discussed at the end of the chapter.
\end{abstract}

Keyword: Rice bran oil; Microwave assisted extraction; Biodiesel; Milling 